\title{
Applicability and Organisation of the Competitive Dialogue in Operator Models
}

\author{
Michael Jürgen Werner
}

(C) ERA 2011

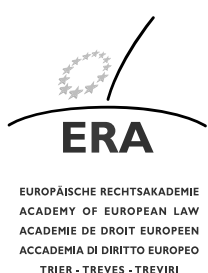

Abstract This paper describes the structured "competitive dialogue" between the contracting public authority and private operators/potential bidders introduced by the 2004 Public Sector Directive. The author takes us through all phases of the procedure - the pre-dialogue phase, the dialogue phase and the tender phase, highlighting their specific requirements, pitfalls and advantages for bidders and public authorities. He also discusses the evaluation phase and analyses a number of evaluation criteria.

Keywords Competitive dialogue $\cdot$ Operator models $\cdot$ Public procurement $\cdot$ Public sector contracts · Public private partnership PPP · Tender · Evaluation criteria

\section{For John Toulmin}

His Honour Judge John Toulmin CMG QC FKC has been an extraordinary contributor to the legal profession in Europe and was particularly active as an adjudicator in construction law. When appointed senior circuit judge at the Technology and Construction Court (TCC) he managed complex civil litigation cases. John Toulmin realised the importance of alternative dispute resolution in these cases and carried out the TCC Court Settlement Process enabling TCC judges to resolve disputes outside of litigation. Also in the field of public procurement, it is not uncommon that notoriously complex procedures give rise to contentious issues, many of which could often be more efficiently resolved by mechanisms other than litigation. The competitive dialogue procedure is designed to deliver the best results for contracting authorities

M.J. Werner LL.M ( $\varangle)$

Partner Norton Rose LLP, Brussels, Belgium

e-mail: michaeljuergen.werner@nortonrose.com 
in particularly complex projects ${ }^{1}$ and should help to avoid contention to arise during the procurement process.

\section{Overview}

This article shall give an overview of the practical application of the competitive dialogue procedure as it has been developed in the EU Public Sector Directive, 2004. ${ }^{2}$

The "competitive dialogue" public procurement process is a procedure in which any economic operator may request to participate and where the Contracting Authority conducts a dialogue with pre-qualified candidates with the aim of developing one or more suitable solutions which meet its requirements. It is on this basis that selected candidates are invited to tender.

The competitive dialogue is a procedure which is open to the ideas and innovations of market participants. The companies which participate in the dialogue are supposed to introduce their ideas during the dialogue phase and, together with the Contracting Authority, find the most suitable solution.

The decisive advantage of the competitive dialogue process is that the Contracting Authority can develop a solution together with participating companies during the procurement procedure for all cases in which the Contracting Authority is not able objectively to define the technical means capable of satisfying their needs or objectives (technical complexity) and/or is not able to specify the legal and/or financial make-up of the project (financial complexity). ${ }^{3}$ The finding whether there is an "objective impossibility" in this sense remains largely at the discretion of the Contracting Authority, but it must not be due to any fault on the part of the authority. ${ }^{4}$

\section{The Competitive Dialogue Process}

\subsection{Pre-dialogue Phase}

At the beginning of a competitive dialogue process, the Contracting Authority has to make several decisions. The issues to be clarified are basically the same as those

\footnotetext{
${ }^{1}$ The aim of the competitive dialogue is to introduce more flexibility into the procurement process, though there has been criticism that it created complexity and uncertainty.

${ }^{2}$ Directive 2004/18/EC of the European Parliament and of the Council of 31 March 2004 on the coordination of procedures for the award of public works contracts, public supply contracts and public service contracts (Public Sector Directive, OJ L 134, 30.4.2004, pp. 114-240); Article 1(11). Individual Member States however retain a margin of discretion in implementing public procurement directives.

${ }^{3}$ The competitive dialogue will typically be used for integrated transport infrastructure projects or those involving complex and structured financing. Article 1(11) (c) of the Public Sector Directive sets out the circumstances in which contracts can be considered particularly complex. By way of example, legal or financial complexity may arise in circumstances where the contracting authorities cannot foresee whether or not economic operators will be prepared to accept a certain level of economic risk - See further European Commission Explanatory Note - Competitive Dialogue - Classic Directive, document CC/2005/04 of 5.10.2005 at para 2.3.
}

${ }^{4}$ Werner [5], p. 21. 
which arise in the negotiated procedure. This will include setting clearly defined objectives and elaborating a fully developed business case as well as identifying any relevant constraints or risks. For example in big road infra-structure projects, this will include the definition of the traffic routing, the securing of the necessary budget required for financing the project and conducting a preliminary economic feasibility study.

Setting the specification criteria is of particular significance in the pre-dialogue phase. Although these are published at the same time as the publication of the public procurement procedure, irrespective of the type of procurement and to the maximum possible extent, special considerations apply in the case of the competitive dialogue. Here, it is the intention of the Contracting Authority to find possible solutions for the implementation of the specific project at least partly in the dialogue with participants. The Contracting Authority should therefore carefully consider its goals and preferences before the opening of the procedure in order to determine the appropriate specification criteria.

A second challenge is to organise and implement the competitive dialogue in a goal-oriented and efficient way. The topics for the dialogue are to be defined and, to the maximum extent possible, it is to be decided with which result the dialogue to individual topics is to be concluded. This revolves around the question as to whether the essential dialogue topics are to be determined by the Contracting Authority, or whether the bidders are free to choose a solution (perhaps within set limits).

The public authority therefore has to answer certain questions prior to the formal opening of the procedure.

For a public private partnership (PPP) project, the preparatory activities can be divided into the following three steps:

(1) Conducting a "PPP adequacy" test

(2) Collection of key data for the project

(3) Conducting a preliminary economic feasibility test (including a feasibility study, where appropriate)

Only the second step must be conducted by the Contracting Authority itself, the first and the third steps, although they are the authority's responsibility, can be conducted by third parties.

\subsubsection{Collection of Key Data for the Project}

Before initiating the procurement process, the Contracting Authority has to make the following decisions and collect information on the following issues:

- Technical requirements (e.g. necessary purchases of land) should be described as precisely as possible;

- Decision whether the planning approval procedure should be concluded already prior to the procurement process;

- The advantage of a planning approval procedure that has not begun at the time of commencement of the procurement is that the successful bidder's potential engineering innovations may be incorporated into the planning approval. Neither the public authority nor the bidder is in a position, however, to influence the duration 
of the planning approval procedure. Accordingly, the risks and costs connected with the completion date are likely to rise;

- After careful weighing of the project-specific pros and cons and of the specific state of the planning, the public authority has to decide how much discretion to leave to the bidders in their technical offers. Depending on these decisions, one has to set the commencement date for planning approval procedure and procurement procedure;

- The availability of required public funding is to be clarified and the required budgeting steps have to be initiated;

- The relevant funding conditions for financing by way of credit for the public side and also for private funding are to be collected.

\subsubsection{Conclusion}

For projects with innovative technical features, as well as during times of volatile financial markets, it could be beneficial to collect indications as to basic funding conditions of the project through a market approach prior to the procurement process.

\subsection{Preliminary Economic Feasibility Study}

Through an economic feasibility study, it is possible to ascertain whether the project would be more economical as a conventional project or as a public private partnership. The preliminary economic feasibility study is intended to reveal significant information about those project parameters that influence the economic efficiency of an operator model and the way in which they do so.

This analysis is a basis for determining the evaluation criteria. Against the background of scenario analysis, the Contracting Authority can ascertain and decide which objective criteria it deems important, so that it can set the criteria for the procurement and the evaluation criteria accordingly, as well as the weighting of the latter. On the basis of the economic feasibility study and the connected scenario analysis, the Contracting Authority can decide the aspects on which and to which extent (e.g. setting of minimum requirements) it is willing to open a dialogue.

The Contracting Authority thus has to decide already at this stage, to the extent possible, whether it intends to conclude certain dialogue sessions with clear results, which then become standard for all bidders and which will not be specially considered in the evaluation criteria, or whether it would prefer to conclude a dialogue session on specific aspects without a unitary solution. In this case, the evaluation criteria should cover the Contracting Authority's preferences.

Depending on the Contracting Authority's degree of preparation for the project's content and the resulting project-specific goals, a time period of nine to twelve months should be set for the implementation and intensive examination of the economic feasibility study.

\subsection{Preparation of the Competitive Dialogue}

The competitive dialogue is an open outcome procedure which provides the Contracting Authority with a great degree of flexibility. There are no set deadlines for 
the accomplishment of the various phases. Experience has shown that it is recommendable for the Contracting Authority to have concrete expectations with regard to its requirements and that the competitive dialogue has to be structured prior to its commencement. From an organisational perspective, it is therefore recommended that the Contracting Authority sets a schedule for the procedural process. It should furthermore determine the number of participants with whom it intends to enter into the dialogue phase and structure the dialogue phase accordingly. Tight process management is required by the Contracting Authority. This requires sufficient personnel to accompany the process on behalf of the Contracting Authority.

\subsection{Pre-qualification Phase}

The competitive dialogue starts with a pre-qualification phase, which is in essence the same as the one for the structured negotiation procedure.

\subsubsection{Publication}

The Contracting Authority should publish its contract notice inviting "requests to participate" in which it sets out is "needs and requirements". With regard to the content of the publication, one should differentiate between obligatory and facultative publications. ${ }^{5}$

The obligatory content of the publication should contain, inter alia:

- Deadlines for applicants' submissions; and

- Minimum criteria regarding participants' capabilities.

The facultative content of the publication should contain, inter alia:

- Award criteria and their respective weighting; and

- Whether or not the Contracting Authority intends to conduct the dialogue in various phases and to reduce the number of solutions. ${ }^{6}$

The details of the project, whether it is intended to limit the number of participants that will be invited to participate, the award criteria as well as a description of the process of the dialogue phase should be set out in the contract notice. For reasons of legal certainty and transparency it is, however, important to communicate all important information as soon as possible, as the information can have an impact on the decision of potential candidates to participate and develop solutions. ${ }^{7}$ It should be remembered, however, that the essential elements of the publication and description may not be changed after publication.

\footnotetext{
${ }^{5}$ The criteria for qualitative selection are set out in Chap. VII of the Public Sector Directive.

${ }^{6}$ According to Article 29(4) of the Public Sector Directive, contracting authorities may provide for the procedure to take place in successive steps in order to reduce the number of solutions to be discussed during the dialogue stage. The contract notice must indicate where this procedure is to be used.

${ }^{7}$ See Telles [2], page 3 (18).
} 


\subsubsection{Selection of Participants to the Dialogue}

As in the structured negotiation procedure, the end of this phase is followed by the selection of participants for the dialogue phase.

- In a first step, the suitability of applicants has to be verified, i.e. their technical qualifications, capabilities and reliability. Should an applicant fail to fulfil a minimum requirement he will be excluded from the procurement procedure;

- There may be a second step, should the Contracting Authority decide to limit the number of participants to the dialogue phase. Here, it should be verified which of the bidders fulfil the objective and non-discriminatory criteria and provisions.

When selecting participants for the dialogue, the Contracting Authority not only has to find those applicants which can be expected to deliver flawless performances, but it should also ascertain whether they are in a position to develop the contents of the contract and various solutions in the dialogue phases together with the Contracting Authority.

\subsubsection{Content of the Descriptive Document}

According to the European Commission the project description is equivalent to the usual bidding documents. It may, however, be "less detailed and/or more prescriptive than "normal' specifications" 8 and no particular form is required. The descriptive document is the term used in the Public Sector Directive for the document that might normally be referred to as the outline specification or output specification. ${ }^{9}$ The description may contain legal, administrative and/or contractual standards which will form part, amongst others, of the basis for procedure and the elaboration of the tenders. The description should give a clear and comprehensive presentation of the required performances to enable the participants to discern all decisive requirements and circumstances for the preparation of the draft and for the tender. The purpose of the performance as well as the technical, commercial, design and functionality requirements should also be provided. Only then can it be expected to receive comparable solution proposals and tenders which fulfil the Contracting Authority's requirements during the competitive dialogue and be in a position to evaluate them.

The public authority has to give participants a performance description in which the minimum requirements and cornerstones of the public private partnership are set out.

\footnotetext{
${ }^{8}$ European Commission Explanatory Note - Competitive Dialogue - Classic Directive, document CC/2005/04 of 5.10.2005, para 3 .

${ }^{9}$ Arrowsmith [1], para. 10.13. 


\subsection{Dialogue Phase}

\subsubsection{Organisation and Subject of the Dialogue Phase}

In principle, the Contracting Authority is free in the way it organises the dialogue phase. ${ }^{10}$ The term 'dialogue' refers to a broad process of exchange of information and positions which may be undertaken either through informal discussions or more formal processes. ${ }^{11}$ The Contracting Authority has to take great care, however, to comply with the established EU procurement law principles of transparency, freedom of competition and freedom from discrimination.

The aim of the dialogue phase is to find solutions for the Contracting Authority's needs and to devise the optimal way in which to meet its requirements.

Contrary to the structured negotiation procedure, bidders are not bound by their tenders throughout the dialogue phase. They can terminate their participation in the competitive dialogue at any time. This flexibility is necessary for participants as the content of the performance to be delivered is not set out in detail at the start of the dialogue procedure and should be developed together with the Contracting Authority. Only the tender submitted during the tender phase becomes binding on bidders.

It should be kept in mind that the danger of a participant leaving the dialogue procedure increases along with the duration of the dialogue. The Contracting Authority should thus try to conduct the dialogue phase quickly. Should only financing and/or legal questions form part of the dialogue, then it should be possible to conclude this phase within approximately six months.

\subsubsection{Setting the Awarding and Evaluation Criteria}

It should be noted that the award criteria cannot be changed during the procedure for reasons of equal treatment, as the Contracting Authority would otherwise be able to change the award criteria at a time when it has already knowledge of an individual bidder's proposed solution.

In practice, the description of the appropriate award criteria constitutes a great challenge for the Contracting Authority. It is difficult to set the relevant award criteria at this point in time if it does not have knowledge about solution proposals. This problem could be addressed if, during the process of the dialogue phase, the Contracting Authority could add sub-criteria and specify the awarding criteria, which could be communicated to the participants at the beginning of the tender phase.

\subsubsection{Opening the Dialogue Phase}

There are two variants for opening the dialogue phase:

\footnotetext{
${ }^{10}$ The margin of discretion of the contracting authority is however disputed on this - see Treumer [3], at page 313, (2006) 15 P.P.L.R. Issue 6.

${ }^{11}$ Arrowsmith [1], para. 10.25.
} 
- The Contracting Authority can request that the dialogue participants submit conceptual solutions on the basis of the specifications set out in the descriptive document by a certain deadline; or ...

This variant is particularly useful should the Contracting Authority already have a comprehensive and detailed description. It may be more time consuming, but this variant allows the Contracting Authority to review and assess the participants' proposed solution and to prepare for the discussions.

- ... alternatively, the Contracting Authority has the possibility to inform all participants about the project and the procedural process in a kick-off meeting before they present their first proposals.

This variant provides for a quick start to the procedure.

General experience shows that negotiations are, however, more focussed when written proposals exist which can form the basis of the discussion. If the requirements and needs of the Contracting Authority can be described, then it is preferable to have participants submit conceptual proposals in writing. For this reason, the opening of a dialogue through a kick-off meeting should only be used if the Contracting Authority is unable to concretely establish its needs due to the complexity of the project.

\subsection{4 "Rules of the Game" for the Dialogue Phase}

The dialogue can deal with all aspects of the project. The precise way to conduct the dialogue phase is not prescribed in detail in the framework legislation. Its cornerstones are the competition principles as well as the fundamental EU law principles of confidentiality, transparency and equal treatment.

This means in detail:

- At the end of the dialogue phase, the Contracting Authority should be in a position to identify a common solution on the basis of which the participants submit their tenders. One has to take care, however, that there are sufficient tenders in the final phase to guarantee a real competition;

- The Contracting Authority has to ensure at all times that all participants have the same amount of information and that none has advanced information. The Contracting Authority has to give every participant the same opportunities, information and deadlines.

To avoid any suspicion of discrimination, the Contracting Authority should always minute the outcome of any discussion it has with participants, have it signed and make it available to the other participants. Here one has to be very careful not to disclose confidential information. The prohibition of discrimination thus is opposed to the other important imperative of confidentiality and the protection of business secrets. $^{12}$

\footnotetext{
${ }^{12}$ In certain Member States, including the UK, contracting authorities may reveal solutions or aspects of other candidates' solutions on the condition that the candidate agrees. This allows the authority, where a particularly interesting or attractive solution has been identified, to receive tenders from other candidates. For details of the procedure in the UK see "Competitive Dialogue in 2008" OGC/MMT joint guidance on using the procedure, p. 6, para 11.
} 
- Due to the principle of confidentiality, negotiations with each participant have to be conducted separately, unless they agree on a collective dialogue.

Furthermore, it should be noted that next to the obligation of confidentiality which is inherent in procurement law, intellectual property rights also have to be observed, in particular the protection of copyright.

- The Contracting Authority may ask the participants to concretise in writing the proposed solutions which were advanced during the discussions. In an iterative process, the Contracting Authority may thus adopt and develop the performance description.

- The Contracting Authority may further subdivide the dialogue phase into so-called dialogue sessions.

Individual dialogue sessions are used to reduce the number of offers. Although the exclusion relates to the proposals, the EU Commission believes that in the majority of cases it can be expected that a participant in the dialogue will only propose a single solution, so that the exclusion of a solution is equivalent to the exclusion of the relevant participant. ${ }^{13}$ In a successive exclusion of solutions, the Contracting Authority needs to be mindful that a minimum of competition remains. The decision to exclude a solution has to be made on the basis of awarding criteria and the affected participant has to be informed in a timely manner about the decision.

In case of the successive exclusion of solutions and thus the potential exclusion of participants, it should be ensured by reason of the competition principle that a sufficient number of participants remain who will submit tenders. It therefore seems appropriate only to conduct several dialogue sessions when there are more than three participants at the beginning of the dialogue phase.

Should the subject of the dialogue only concern points relating to financing and legal drafting then the dialogue phase should not be subdivided into several dialogue sessions. Experience has shown that one should provide for two to three appointments with each applicant for the negotiation of financing issues.

It is recommended that not only financing issues, but also technical issues be the subject of the dialogue. In these cases, it may be appropriate to plan two dialogue sessions within the dialogue phase. One dialogue session should discuss techniques, the other financing.

\subsubsection{Concluding the Dialogue Phase}

3.5.5.1 One or Two Solution Proposals? The Contracting Authority has to request participants to submit their final tenders on the basis of the submitted solutions which were further explained during the dialogue phase.

(a) Submission of tenders on the basis of differing solution proposals

Due to the differences between the tenders, it is difficult to evaluate and to compare them. It is apparent that decision by the Contracting Authority favouring one solution over the other carries a great risk of being challenged in a review procedure before the competent courts.

${ }^{13}$ European Commission, Explanatory Note "Competitive Dialogue - Classic Directive", CC/2005/04 of 5.10.2005 at p. 9. 
(b) Submission of tenders on the basis of a unitary performance description

To establish comparability of the tenders, it is recommended that applicants submit tenders on the basis of a unitary solution. This means that the Contracting Authority publishes a unitary performance description for all bidders, which either completely adopts a solution developed during the dialogue phase, or constitutes a combination of the various solutions proposed by the participants during the dialogue phase. One has to be careful to obtain a clear express acceptance from the participant or participants whose solution will be adopted wholly or in part, prior to the solution being made available to all other participants.

For reasons of legal certainty and procedural efficiency, it is preferable that the Contracting Authority prescribes a unitary solution. Despite the special sensitivity required in relation to principles of confidentiality, the other principles of equality and transparency point towards this procedure.

To establish comparability of the solutions and in order to achieve the greatest degree of legal certainty in a subsequent evaluation of the tenders, it should be the aim of the dialogue that there is only one proposed solution after the conclusion of the dialogue phase in which all participants of the dialogue submit their tenders.

3.5.5.2 Preparation of the Tender Phase It is important that there is a common understanding about the content of the unitary solution proposal between the Contracting Authority and the participants at the end of the dialogue phase, because one cannot negotiate basic elements of the tender after the conclusion of the dialogue phase and the submission of the tenders by the participants. After this stage, only specifications, clarifications and amendments are permitted.

If it is assumed that the Contracting Authority could continue to write its performance description after the negotiations with the bidders, in which it identified the solutions for its needs and requirements, it then has to be considered whether the Contracting Authority at the conclusion of the dialogue phase would require the participants to submit a proposed solution on its preferred solution. Should it use participants' proposed solution, it has to obtain the consent of the relevant participant (on the relevant basic principles, the principle of confidentiality, and the obtaining of potentially required acceptances in particular, see above). If the required acceptances are not received the Contracting Authority can require the participants to submit their own solutions or try to draft a unitary solution under observance of the principles of confidentiality.

The demand for the submission of solution proposals allows the Contracting Authority to ascertain whether tenders will be submitted and whether these preliminary tenders are suited to fulfil the needs and requirements of the project. Should this not be the case, the Contracting Authority has the opportunity to clarify its performance description accordingly and to concretise it. If, following these adaptations, there is still no solution submitted that conforms to the Contracting Authority's requirements, it can be assumed that the competitive dialogue has failed.

The participants should have four to six weeks for drafting a solution.

3.5.5.3 Conclusion of the Dialogue Phase The Contracting Authority has to make the conclusion of the dialogue phase formally known. This information has to be provided immediately and in writing. 
The dialogue phase is to be concluded, if:

(a) No solutions are submitted.

Should the Contracting Authority continue to pursue the project, it has to analyse whether the project should be procured anew in the form of a public private partnership or whether it potentially procures conventionally.

(b) Solutions are submitted that satisfy the requirements of the Contracting Authority.

In this case, the Contracting Authority requires the participants to submit their final tender on the basis of the submitted solutions which were further discussed during the dialogue phase. Participants' tenders have to include all details necessary for the implementation of the project.

\subsection{Tender Phase}

\subsubsection{Submitting the Tender}

Once the dialogue is concluded, the Contracting Authority shall require participants to submit their final tender on the basis of submitted solutions which were developed during the dialogue phase. Given the abovementioned reasons, this may mean the submission of tenders on the basis of a unitary performance description. However, Article 29(6) of the Public Sector Directive requires that the Contracting Authority shall ask participants to submit their final tenders "on the basis of the solution or solutions presented and specified during the dialogue". This provision clearly indicates that it is not necessary to establish a single specification against which providers will submit their final tenders. They may each submit their own solution, subject to the requirements laid down by the Contracting Authority. ${ }^{14}$

\subsubsection{Drafting a Document on which the Applicants Submit a Tender}

The performance description should be the optimised version of the description published at the beginning of the dialogue phase.

While drafting, one should keep in mind that following the submission of the tenders there is no room left for negotiation. Therefore all tenders must contain all essential elements required and necessary for the performance of the project. The performance description should thus be as detailed as possible. This is also important to guarantee the comparability of the tenders. The Contracting Authority may, however, within those limits, provide for functional elements, i.e. variables in the performance description which can be interpreted by the bidders. It is recommended that applicants receive a unitary performance description which contains the draft of a contract and submit their tender on this basis.

When altering the performance description, it is important not to infringe any of the bidders' rights. This means that technical solution proposals developed by the

${ }^{14}$ Arrowsmith [1], para. 10.31 . 
bidder and discussed with the Contracting Authority during the dialogue phase, can only be forwarded with the consent of the relevant participant. Potential copyright implications are to be assessed separately. If the Contracting Authority combines the various drafting elements in its performance description anew, then the acceptance may be dispensed with, if these concerns were already known and have been discussed.

For the drafting of the final performance description, one should allow approximately six weeks.

The deadline for the development of tenders should not be too short. Forty days should be used as a reference point.

\subsubsection{Concretising and Evaluating the Tenders}

The process of the tender evaluation phase would usually be as follows:

(a) As a first stage, the Contracting Authority has to assess the submitted tenders in order to ascertain whether the tenders contain all necessary details for the implementation of the project. This means that the tenders have to be clear and comprehensive enough for the Contracting Authority to examine and evaluate them, and particularly so that it can ascertain whether the tender meets its requirements and needs (examination on conformity);

(b) Upon the Contracting Authority's request, bidders can make specifications, clarifications and amendments to their tenders. ${ }^{15}$

"Specification" means the concretising of an existing proposition that, in the Contracting Authority's opinion, is too abstract.

"Clarification" is the explanation of ambivalent details, or where the content cannot be understood.

"Amendments" are for fine-tuning. This includes minor changes, so long as they do not distort competition or are discriminatory. ${ }^{16}$

All these acts are permissible only if there is no danger of distorting competition or discriminating against bidders.

(c) Once the Contracting Authority has received its desired clarifications, it evaluates the tenders in a second stage according to their economic feasibility. The evaluation takes place on the basis of the awarding criteria as described in the performance description.

The evaluation of the economic feasibility is done according to the evaluation matrix.

\footnotetext{
${ }^{15}$ Care must be taken that this exercise remains a clarification and not a re-negotiation. This should not involve changes to the basic features of the tender, see "Competitive Dialogues and the Scope for Discussion after tenders and before selecting the Preferred Bidder.

${ }^{16}$ The concept of "fine-tuning" is set out in Article 29(6) of the Public Sector Directive. According to Professor S. Arrowsmith, this should be permitted only in so far as these do not have an impact on the outcome of the competitive dialogue procedure. For an analysis of this view, please see Verschuur [4], at p. 327.
} 
(d) The Contracting Authority can furthermore require the bidder of the most economically feasible tender to further explain certain details of the tender or to confirm the covenants contained in the tender.

"Explain" in this context means that the bidder comments his statement to resolve a lack of clarity.

"Confirm covenants contained in the tender" means that a non-binding statement in the tender may become legally binding for the Contracting Authority.

The possibility of receiving confirmation from the Preferred Bidder is a practical necessity. This affects e.g. the financing confirmation from the financing banks, certificates of bonds and certain insurance policies.

All in all, the drafting of the performance description by the Contracting Authority, the drafting of tenders by the bidders and the finalisation and evaluation of the tender should not take longer than four months.

\subsection{Award and Formation of the Contract}

The result of the economic feasibility study has to be known prior to awarding the contract. Although the Contracting Authority has to conduct the economic feasibility study, it can, however, transfer this task to a third party. Upon conclusion of the economic feasibility study, the remaining bidders will be informed in advance about the result of the procedure.

It is to be noted that, following the award of the contract, the successful bidder should be granted a period of approximately six weeks to finalise financing with the banks.

\subsection{Cost Reimbursement}

In the performance description, the Contracting Authority should fix the common calculation basis for an appropriate reimbursement of costs. Only those costs should be reimbursed which arose out of the timely submission of documents which the Contracting Authority required and for which expenditures is beyond what is usually expected for procurement processes.

\subsection{Possibilities to Terminate the Overall Procedure}

\subsubsection{Termination by the Applicant}

Until submission of a tender, participants are not bound by their statements and solution proposals. They can terminate their participation in the competitive dialogue at any time.

\subsubsection{Termination of the Procedure by the Contracting Authority}

Should the Contracting Authority discover at the end of the dialogue phase that no solution could be found which meets its needs and requirements, it should declare the dialogue phase and thus the competitive dialogue terminated. 
Should the Contracting Authority decide to terminate at an earlier point in time or even at the tender phase, it is to be noted that, although it cannot be forced to award a contract, the decision to cancel the competitive dialogue nevertheless has to comply with procurement law. Such a decision by the Contracting Authority can be challenged by a participant in a court review procedure.

\section{Evaluation Criteria}

\subsection{Aims of the Evaluation Criteria}

The evaluation criteria are the Contracting Authority's instrument which helps it:

- during the dialogue phase, to identify the preferred solution for a topic out of the many negotiated solution proposals;

- after the dialogue phase, to identify the most economically feasible tender out of the many submitted tenders.

The evaluation criteria reflect substantive goals which the Contracting Authority seeks to realise with the project. The weighting of the respective evaluation criteria reflects the priorities of the Contracting Authority's goals.

The criteria set at the beginning of the procedure thus serve to identify a unitary solution during the course of the dialogue, on which all bidders submit their tenders. Even where a unitary solution is desired by the Contracting Authority but this does not come about - perhaps due to the inability to obtain the acceptance of a bidder to use its solution proposal as the standard for a single preferred solution for all bidders - then the evaluation criteria defined initially are used for the evaluation of the tenders. As the criteria remain the Contracting Authority's instrument to evaluate the tenders, irrespective of the solution developed during the course of the dialogue, this highlights the importance of a diligent definition and prioritisation of the criteria according to the Contracting Authority's goals.

The early publication of the evaluation criteria and description also leads to increased transparency for the procedure. At the same time, the potential bidders receive guidance as to the Contracting Authority's main focus and can submit a tender which is better suited to the Contracting Authority's project-specific needs.

The requirements as to the evaluation criteria and the definition of their content will be described in further detail below. It will be assumed that the bidders' general qualification was already assessed and evaluated during the pre-qualification phase and thus does not form part of the evaluation of the tenders.

\subsection{Requirements for the Evaluation Criteria}

The most economically feasible tender is the tender with the highest marks for a combination of technical, commercial and other features. The evaluation criteria reflect the preferences and priorities of the Contracting Authority. To review the Contracting Authority's goals one could use the economic feasibility study as standard of comparison. Irrespective of the evaluation criteria's content, the following general requirements should be satisfied. The criteria should be: 
- clearly defined;

- verifiable;

- grant the Contracting Authority a certain margin of discretion;

- comprehensive, covering the Contracting Authority's goals;

- free of repetitions and contradictions;

- practicable for the Contracting Authority;

- applicable to the existing information for the Contracting Authority.

Furthermore, in defining the evaluation criteria, the following peculiarities of the competitive dialogue should be considered.

The competitive dialogue challenges the Contracting Authority to set criteria for the evaluation of proposed solutions prior to the commencement of the dialogue phase, although the concrete content of the project, at least in the area in which the dialogue is to be held, will only be defined during the course of the dialogue. During the dialogue phase, the Contracting Authority may not alter the evaluation criteria set out in the contract documents. ${ }^{17}$

Furthermore, it may be possible on the basis of the defined evaluation criteria to exclude proposals of the dialogue partners during the dialogue phase, or to identify a unitary solution for certain topics. The evaluation criteria also have to constitute a manageable standard for these scenarios.

\subsection{Types of Evaluation Criteria}

In relation to the evaluation of the defined criteria, one can differentiate structurally between several case groups. Essentially, scalable and non-scalable criteria can be differentiated. With scalable criteria, the bidder's tender will be awarded a certain number of points according to the degree to which it meets the criterion. Non-scalable criteria, however, exclusively assess whether the tender fulfils certain requirements. It does not evaluate how or how well the requirements are fulfilled.

Furthermore, evaluation criteria can be differentiated between those which constitute minimum criteria and those which do not. Should a minimum criterion not be met, then the relevant tender has to be excluded. These features can also be combined:

Table 1 Types of evaluation criteria

\begin{tabular}{|c|c|c|}
\hline Scalability & Evaluation & Example \\
\hline Non-scalable & Ranking & $\begin{array}{l}\text { Decision of the bidder to assume completely a } \\
\text { certain risk or not to assume it completely }\end{array}$ \\
\hline Scalable & Ranking & Net present value of the initial funding \\
\hline Scalable & Minimum criteria plus ranking & $\begin{array}{l}\text { Minimum requirements for operation services, } \\
\text { where additional services are offered then add } \\
\text { further evaluation points }\end{array}$ \\
\hline
\end{tabular}

${ }^{17}$ Cf. ECJ, Case C-532/06, Lianakis, para 43; Case C-331/04, ATI EAC and Others 2005 ECR I-10109, para 24. 
Scalable criteria award a certain number of points for a tender which depends on the degree to which the aim of the evaluated feature is achieved. So long as clearly measurable features of a tender are concerned, e.g. the net present value or the necessity for land, the features can be awarded a clear number of points. Should it not be possible to quantify clearly and compare individual criteria then a benefit analysis can be conducted.

The two types of evaluation criteria can also be combined by setting a minimum quality standard which will be evaluated with a minimum criterion. A quality which supersedes the set minimum quality standard can then be evaluated additionally with a scalable criterion. This can be used for example when a certain standard is required for the operation services, but where the bidders should have the discretion to offer a higher standard.

When the tenders are received, every tender can be evaluated according to whether or not it achieves defined goals. The overall evaluation and the overall benefit of a tender then results from the sum of the degree to which the tender-specific criteria have been achieved, which is weighted according to the weighting factors.

\subsection{Content Formation of Evaluation Criteria}

When identifying the most economic tender, the offered price-performance ratio is evaluated, i.e. commercial aspects as well as technical and other features of the proposed solution are evaluated. In this regard, one should provide, at least for all features which are not specifically prescribed, (i.e. all areas where the bidders have discretion) an evaluation criterion. For a unitary solution which was developed during the course of the dialogue, one has to evaluate according to the previously defined criteria. It has to be kept in mind that those parts of the tender which are identical (e.g. regarding a risk allocation which is the same for each bidder) should be assessed solely on the basis of their compliance with the respective standard (in the sense of a minimum criterion).

\subsubsection{Evaluation of the Technical Part of the Offer}

So long as a clear technical performance description or a descriptive specification of the required performance is set out in the tender documents, a separate evaluation of the technique can potentially be omitted. Usually however, a bidder for operator models will be left with discretion as to the technical development of the project.

In this case the evaluation criteria are as follows:

- the quality of the technical solution;

- the architectural development;

- environmental aspects;

- the quality of the offered operator concept.

The selected criteria can be further specialised through the definition of sub-criteria, which also serve to give bidders a better idea of the goals of the Contracting Authority. It is furthermore possible to set minimum requirements and to evaluate additionally the quality of the implementation of the minimum requirements. As to how appropriately this can be implemented, this is to be determined on a project-specific basis. 


\subsubsection{Evaluation of the Financial Part of the Tender}

The evaluation of the financial part of the tender is usually concerned with measuring the financial burden carried by the Contracting Authority. In connection with this, the risk allocation incorporated in the tender can be evaluated, if it is not clearly prescribed. Risks that remain with the public authority always translate into a financial burden when they crystallise. If the invitation to tender permits the bidder to determine, for certain risks in its own discretion, the degree of risk which it intends to carry, then the degree of risk allocation is also to be evaluated.

Various features could be used as evaluation criteria for the financial part of the tender. Their applicability also depends on the selected structure for the competitive dialogue.

4.4.2.1 Net Present Value of the Contracting Authority's Performances This criterion entails the net present value of all payments to be performed by the Contracting Authority to the successful tenderer, e.g. the initial funding or potential further financial performances such as a terminal value compensation. Here the discount factor should be published together with the invitation to tender. The tender with the lowest net present value is awarded the highest number of points.

\subsubsection{Sum of Nominal Payments Depending on the Contracting Authority's goals,} it may also be sensible to evaluate the sum of nominal payments in addition to the net present value. In the calculation of the net present value payments that are to be made during time periods which are further away are weighted less than payments which are to be made in nearer periods of time. For the sum of nominal payments, however, all payments are weighted equally.

4.4.2.3 The Acceptance of Certain Risks Should the Contracting Authority leave it up to the bidders' discretion as to whether to accept certain risks, at least in part, then the actual acceptance of risk is to be evaluated. This criterion is only a scalable criterion if the Contracting Authority does not prescribe a clear unitary solution, but leaves the bidders with some choice.

To maintain an overview of the effort for administration and evaluation, and at the same time in order to increase transparency for the bidders, it is advisable not to leave bidders with unlimited discretion as to the extent of risk acceptance, but instead to prescribe certain levels and to publish the respective evaluation points.

4.4.2.4 Security of the Financing This concerns the evaluation of the expected stability of the bidder's specified financing concept. Here, evaluations take place for example in relation to potential limitations or conditions in the Term Sheet or in relation to the number of the indicative financing commitments.

This criterion is only available if the bidders' tenders are required to be accompanied by an indicative financial offer and, only if after the conclusion of the Contracting Authority's assessment and evaluation periods the Preferred Bidder has to submit a definitive financing commitment.

If this criterion is considered it should be of only minor importance in the overall evaluation of the tenders. 
If binding financing confirmation is required at the time the tender is submitted, the evaluation criteria "financing security" is omitted. Instead, evaluation points should then be added to the criterion "net present value of the Contracting Authority's performances".

The criterion "risk", if prescribed in a relation to a unitary solution as described above, becomes a minimum criterion, the fulfilment of which is exclusively test. In this case, evaluation points should then be added to the criterion "net present value of the Contracting Authority's performances". The "net present value" of the Contracting Authority thus could be weighted at $75 \%$ in the present example.

The selected evaluation criteria and their weighting in relation to one another are, however, to be amended and added on a project-specific basis.

\section{References}

1. Arrowsmith, S.: The Law of Public and Utilities Procurement (2005)

2. Telles, P.: Competitive dialogue in Portugal. Public Procure. Law Rev. (2010)

3. Treumer, S.: The field of application of competitive dialogue. Public Procure Law Rev. 15(6) (2006)

4. Verschuur, S.: What is fine-tuning etc? Public Procure. Law Rev. 15(6) (2006)

5. Werner, M.J.: In: A Practical Guide to PPP in Europe, Chapter 2 (European Union) (2008) 